\title{
Synthesis and Characterization of 2-Chloro-6-fluorobenzylalcohol using Electrochemical Approach
}

\author{
Ritu Saharan \\ Department of Chemistry, University of Rajasthan, Jaipur, 302004, India \\ Available online at: www.isroset.org \\ Accepted: 17/Aug/2018, Online: 30/Aug/ 2018
}

\begin{abstract}
Electrochemical Synthesis and characterization of 2-Chloro-6-fluorobenzylalcohol is investigated. The electrochemical behavior and electrochemical reduction of 2-Chloro-6-flourobenzaldehydeis has been carried out using cyclic voltammetry having glassy carbon electrode (GCE) and constant current electrolysis respectively. Reduction reaction peaks at various scan rate and $\mathrm{pH}$ has been reported. In kinetic parameters study, the process has been found to be diffusion controlled. The synthesized 2-Chloro-6-fluorobenzylalcohol has been characterized using IR, ${ }^{1} \mathrm{HNMR}$ and Mass spectral analysis.
\end{abstract}

Keywords-Cyclic voltammetry, Electrochemical Synthesis, Constant current electrolysis, Glassy carbon electrode, Electrochemical reduction

\section{INTRODUCTION}

The electrochemical technique is a methodology in which either oxidation or reduction of substrate yields the desired product [1-2]. In electrochemical synthesis the main role is of electron. It is produced during the electrochemical reaction and participated as a reagent in reaction. It is pollution free therefore it eliminates the use of harmful reagent [3]. This makes simple work up procedure, avoids formation of undesirable byproducts, economically viable, ecofriendly in nature, products are pure and in good yield [4-5].

The kinetics and mechanisms of redox reactions is being carried using cyclic voltammetry. The signals from cyclic voltammetry are helpful to predict optimum conditions for electrolysis process [6-8]. Cyclic voltammograms are also useful to know the mechanism of organic reaction [9$10]$.

In agricultural derivatives and pharmaceutical drugs, 2Chloro-6-fluorobenzalalcohol is utilized as intermediates synthesis.

In keeping view of all mentioned above applications, presented work describes the electrochemical reduction of 2Chloro-6-flourobenzaldehyde to the corresponding aromatic alcohol 2-Chloro-6-fluorobenzyl alcohol using cyclic voltammetry (to estimate electrode reaction) and constant current electrolysis. Biotransformation via Baker's Yeast has also been employed to synthesize aromatic alcohols and these synthesized products possess potential antibacterial properties against the pathogenic bacteria [11-12].

Organization of the paper (Rest of the paper is organized as follows, Section I contains the introduction of Electrochemical Synthesis, Section II contain the materials and methods adopted, Section III describes results and discussion, and Section IV concludes research work).

\section{MATERIALS AND METHODS}

All the used chemicals in present study are of AR (analytical reagent) grade. All the solvents have been dried and then distilled out. The required solutions have been prepared using doubly distilled water. Joel (Japan) 300MHZ spectrophotometer has been used to record ${ }^{1} \mathrm{H}$ NMR spectra. Nicolet (USA) FT-IR spectrophotometer has been used to record FT-IR spectra. Mass spectra were recorded from Central Drug Research Institute (CDRI), Lucknow.

\section{Electrochemical Reduction}

The was used for recording .Cyclic voltammograms of 2Chloro-6-flourobenzaldehyde have been recorded on completely computer controlled Basic Electrochemistry System model ECDA-001 at various scan rates and $\mathrm{pH}$ in aqueous methanol. As a supporting electrolyte, Potassium chloride is used. Cyclic voltammograms were obtained using a working electrode of glassy carbon $\left(A=0.1 \mathrm{~mm}^{2}\right)$, reference electrode of $\mathrm{Ag} / \mathrm{AgCl}$ and an auxiliary electrode of 
platinum. All the experiments have been performed at room temperature. Before each electrochemical measurement glassy carbon working electrode has been polished with aluminium oxide $(0.4 \mu)$ with the help of polishing cloth.

For removal of dissolved oxygen from the media, the test solutions have been purged with clean purified and dry nitrogen for $5 \mathrm{~min}$ before the experiments and then blank cyclic voltammograms have been recorded. $1 \mathrm{mM}$ Solution of 2-Chloro-6-flourobenzaldehyde has been added to blank solution followed by setting up the initial potential (IP), final potential (FP), scan rate (SR) and current sensitivity (CS). Finally cyclic voltammograms were obtained.

\section{Constant Current Electrolysis}

Electrochemical reduction of 2-Chloro-6-flourobenzaldehyde has been carried out using constant current electrolysis keeping constant current of $1.0 \mathrm{amp}$ for duration of $06 \mathrm{hrs}$ in aqueous methanolic solution. Experiment was performed using Galvanostat (supplied by OMEGA type ICVD 60/2). In electrolysis for stirring the test solution, a Remi hot plate cum magnetic stirrer (2 M LH model) has been used.

For electrolysis $\mathrm{H}^{-}$shaped glass cell (consisting two compartment) having a fritz glass disc (G-4) has been employed. Stainless steel (SS-316) electrode $(4 \mathrm{~cm} \times 6 \mathrm{~cm})$ has been used as cathode and anode. The Britton Robinson (BR) buffer of $\mathrm{pH} 9.0$ and $\mathrm{CH}_{3} \mathrm{COONa}$ as supporting electrolyte has been used to fill both the compartments of $\mathrm{H}-$ shaped glass cell. By using minimum amount of methanol, 2-Chloro-6-flourobenzaldehyde has been dissolved and poured in the cathodic chamber. Then electrolysis was done at constant current at $1.0 \mathrm{amp}$. Diethyl ether has been used for extraction after the successfully completion of reaction. The synthesized product has been then characterized by melting point measurement, chromatographic and spectral techniques (Table-2 and 3).

\section{RESULTS AND DISCUSSION}

Electrochemical reduction of 2-Chloro-6-flourobenzaldehyde has been illustrated by reaction as below:-

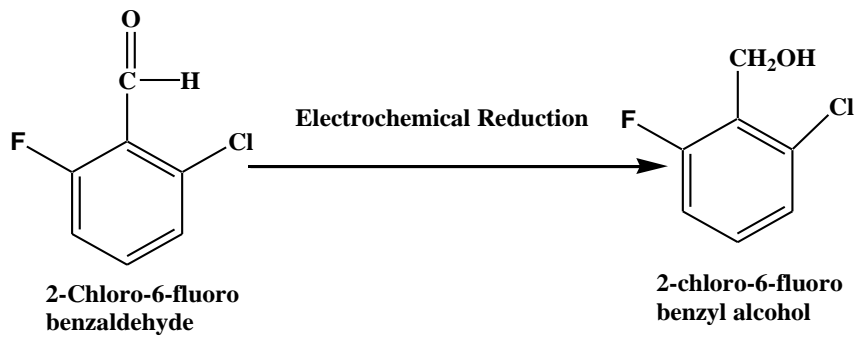

In the cyclic voltammograms of 2-Chloro-6-flouro benzaldehyde at different $\mathrm{pH}$ viz. $\mathrm{pH} 5.0, \mathrm{pH} 7.0$ and $\mathrm{pH} 9.0$ single irreversible reduction peak has been observed because of reduction of $>\mathrm{C}=\mathrm{O}$ group to the respective secondary alcohol to yield final product as 2-Chloro-6fluorobenzylalcohol. Table 1 shows the kinetic Parameters calculated from cyclic voltammograms.

\section{Scan rate effect}

The scan rate effect on Epc (cathodic peak potential) has been investigated. As shown in Figure 1, an increase in scan rate from $100 \mathrm{mV} / \mathrm{s}$ to $500 \mathrm{mV} / \mathrm{s}$, shifts the cathodic peak potential in direction of more negative potentials. This indicates that process of electron transfer is irreversible. The graph between cathodic peak current (Ipc) and square root of scan rate $\left(v^{1 / 2}\right)$ is in line with correlation coefficients near equal to unity (Figure 3 ).

The current process has been found to be diffusion controlled under these scenrio.

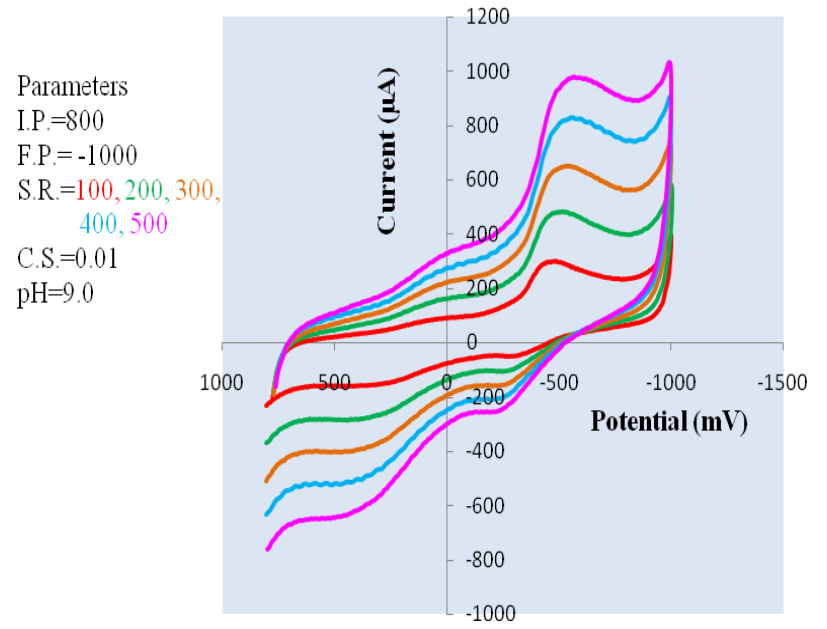

Figure 1. Cyclic voltammograms of 2-Chloro-6flourobenzaldehyde at different scan rates keeping pH 9.0

\section{Effect of pH}

As shown in Figure 2, cyclic voltammograms have been obtained at various $\mathrm{pH}$ viz. $\mathrm{pH}$ 5.0, 7.0 and $\mathrm{pH} 9.0$ and effect of $\mathrm{pH}$ on reduction peak has been observed. From cyclic voltammograms it has been found that a prominent peak has been seen in alkaline medium. So electrochemical reduction is performed extremely good in basic medium. In acidic medium peak remains absent and in neutral medium very weak peak is observed. 


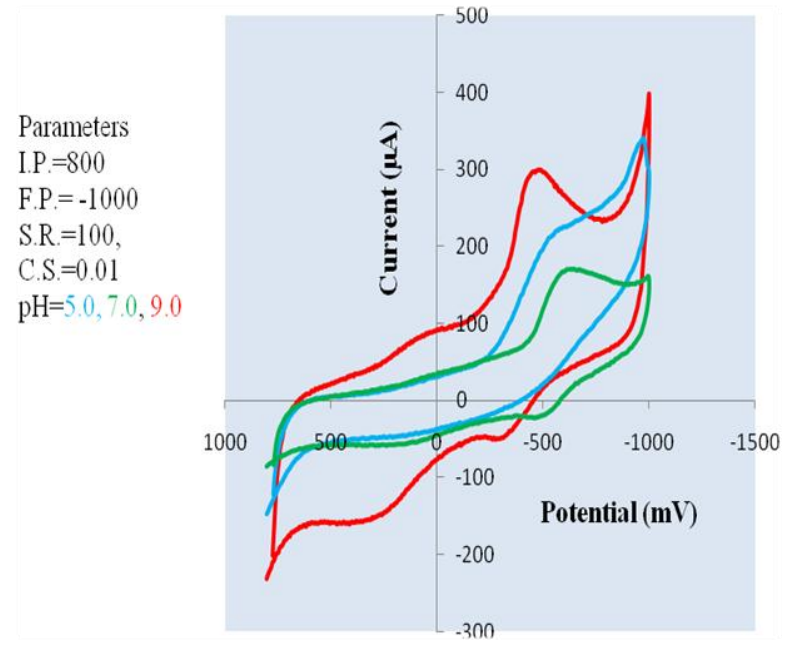

Figure 2.Cyclic voltammograms of 2-Chloro-6-flourobenzaldehyde at different $\mathrm{pH}$

Table 1. Voltammetric data evaluated from cyclic voltammograms of 2-Chloro-6-flourobenzaldehyde

\begin{tabular}{|c|c|c|c|}
\hline $\begin{array}{c}\text { Scan rate } \\
\boldsymbol{v}(\boldsymbol{m} \boldsymbol{V} / \mathbf{s})\end{array}$ & $\begin{array}{c}\text { Cathodic peak } \\
\text { potential } \\
\boldsymbol{E}_{\boldsymbol{p} \boldsymbol{(} \boldsymbol{(} \boldsymbol{V})}\end{array}$ & $\begin{array}{c}\text { Cathodic peak } \\
\text { current } \\
\boldsymbol{I}_{\boldsymbol{p c}}(\boldsymbol{\mu} \boldsymbol{A})\end{array}$ & $\begin{array}{c}\text { peak current / } \\
\text { square root of } \\
\text { scan rate } \\
(\boldsymbol{I} \boldsymbol{p} / \sqrt{\boldsymbol{v})}\end{array}$ \\
\hline 100 & -417 & 352 & 35.2 \\
\hline 200 & -428 & 448 & 35.57 \\
\hline 300 & -459 & 616 & 35.65 \\
\hline 400 & -486 & 789 & 35.5 \\
\hline 500 & -509 & 949 & 35.79 \\
\hline
\end{tabular}

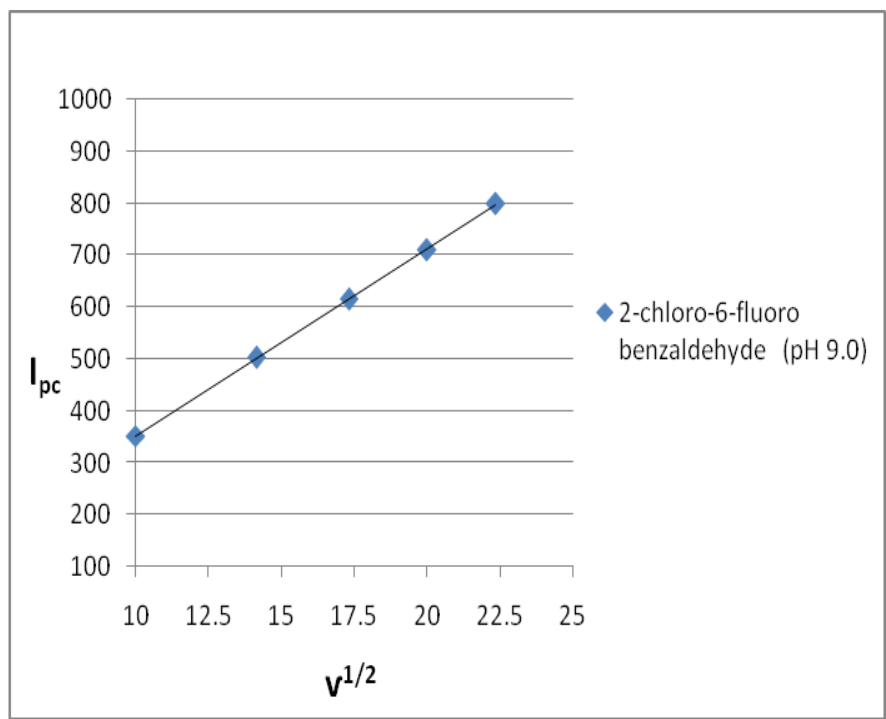

Figure 3. Graphical showing relationship between cathodic peak current $\left(\mathrm{i}_{\mathrm{pc}}\right)$ and $v^{1 / 2}$ for 2-Chloro-6-flourobenzaldehyde at $\mathrm{pH} 9.0$
Table 2. Physical data of 2-Chloro-6-fluorobenzyl alcohol from Electrochemical Reduction

\begin{tabular}{|c|c|c|}
\hline IR Data $\left(\mathbf{c m}^{-1}\right)$ & ${ }^{1} \mathbf{H}$ NMR Data $(\boldsymbol{\delta})$ & Mass Data $\mathbf{~ m} / \mathbf{z}\left(\mathbf{M}^{+}\right)$ \\
& & \\
$3365(\mathrm{OH})$, & $2.1 ; \mathrm{OH}(\mathrm{s})$, & $160\left(\mathrm{M}^{+}\right)$and \\
$3020(\mathrm{Ar} \mathrm{C}-\mathrm{H}$ str), & $4.74 ; 2 \mathrm{H}(\mathrm{s})$, & $162(\mathrm{M}+2)$ \\
$2880-2960(\mathrm{CH}-\mathrm{str})$, & $7.2 ; \mathrm{Ar}-3 \mathrm{H}(\mathrm{m})$ & \\
$1500,1450(\mathrm{C}=\mathrm{C}$ ring & & \\
str), & & \\
$1040(\mathrm{C}-\mathrm{O}$ str primary & & \\
alcohol, & & \\
650-800 (strong & & \\
Aromatic absorption & & \\
as C-H out of plane & & \\
bend. Vib.) & & \\
& & \\
\end{tabular}

Table 3. Spectral data of 2-Chloro-6-fluorobenzyl alcohol from Electrochemical Reduction

\begin{tabular}{|l|c|c|c|}
\hline Product Structure & $\begin{array}{c}\text { Reaction } \\
\text { Time } \\
\text { (in hours) }\end{array}$ & $\begin{array}{c}\text { Melting } \\
\text { Point } \\
\left({ }^{\circ} \mathrm{C}\right)\end{array}$ & $\begin{array}{c}\text { Yield } \\
(\%)\end{array}$ \\
\hline & 6 & 44 & 86 \\
\hline
\end{tabular}

\section{CONCLUSION}

2-Chloro-6-fluorobenzyl alcohol has been synthesized using electrochemical technique and characterization has been done based on analytical as well as spectral data. In electrochemical synthesis the electron is participated in form of reagent and produced in course of the electrochemical process. This overcomes the formation of adverse byproducts, make work up procedure simpler, ecofriendly, easy to handle, cost effective. Hence obtained products are in pure state and good yield.

\section{REFERENCES}

[1] B. Devadas, M. Rajkumar, S. M. Chen, R. Saraswathi, "Electrochemically Reduced Graphene oxidel Neodymium Hexacynoferrate Modified Electrodes for the electrochemical Detection of paracetamol", Int. J. Electrochem. Sci., Vol. 7, pp. 3339-3349, 2012 
[2] RE Clarke, A Kulkarni, S Giddey et al. "Evaluation of solid electrolyte cells with a versatile electrochemical techniques", Ionics, 19, pp. 265-275, 2013, DOI: 10.1007/s11581-012-0749-1.

[3] R. Saharan, "Electrochemical Synthesis and Characterization of 2, 4-Dichlorobenzylalcohol", Ascent International Journal for Research Analysis, Vol. II, Issue IV, 2.1-2.5, 2017

[4] T. Shano, "Electro-organic Chemistry as a New Tool in Organic Synthesis", Springer, New York, 1984.

[5] D. Nematollahi and A. Amani, "Electrochemical synthesis of the new substituted phenylpiperazines”, J. Electroanal. Chem., Vol. 651, Issue1, pp.72-79, 2011

[6] F.R Perez, L. Basaez , J. Belmar and P. Vanysek, "Cyclic voltammetry of 1-(N-hexyl)-3-methyl-5-pyrazolone-based enamines and their chloromanganese(III) and nitridomanganese (V) complexes", J. Chil. Chem. Soc., Vol. 50, Issue 3, pp. 575-580, 2005

[7] A Masek, M Zaborski, E Chrzescijanska, "Electro-oxidation of flavonoids at platinum electrode studied by cyclic voltammetry", Food Chem.,Vol. 127 Issue 2, pp. 699-704, 2011

[8] N.G. Tsierkezos, "Investigation of the electrochemical reduction of benzophenone in aprotic solvents using the method of cyclic voltammetry" J. Solution Chem, Vol. 36(10), pp.1301-1310, 2007

[9] ME Niyazymbetov, "Electrochemical methods in organic synthesis of valuable intermediates" Electrosynthesis, Vol. 3 Issue 2, 1997
[10] GP Mamatha, BS Sherigara, KM Mahadevan, "Electrochemical reduction of 2-acetyl benzofuran and its derivatives at glassy carbon electrode", Indian Journal of Chemical Technology, 14, pp. 566571, 2007,

[11] R. Saharan, J. Joshi, "Synthesis, characterization and antibacterial studies of 4-Hydroxy-3-methoxy-benzyl alcohol and 1-(4-Hydroxy-3methoxyphenyl) ethanol", Journal of Biological and Chemical Research, 33 Issue 1, pp. 529-536, 2016

[12] R. Saharan, "Analysis of Antibacterial Properties of 2 Methylcyclohexanol", International Journal of Scientific Research and Review, Vol. 7 Issue 6, pp. 347-351, 2018

\section{AUTHORS PROFILE}

Dr. Ritu Saharan pursed B. Sc., M.Sc., and Ph.D. Chemistry from MNIT Jaipur in 2005, 2007 \& 2013. She is by profession as Assistant Professor in Department of Chemistry from University of Rajasthan, Jaipur since 2014. She has publication of more than 20 research papers in reputed international journals and conferences. Her main research work focuses on Electro-organic Synthesis and Bio-transformation, Organic Chemistry and Green Chemistry. She has 4 years of teaching and research experience. 